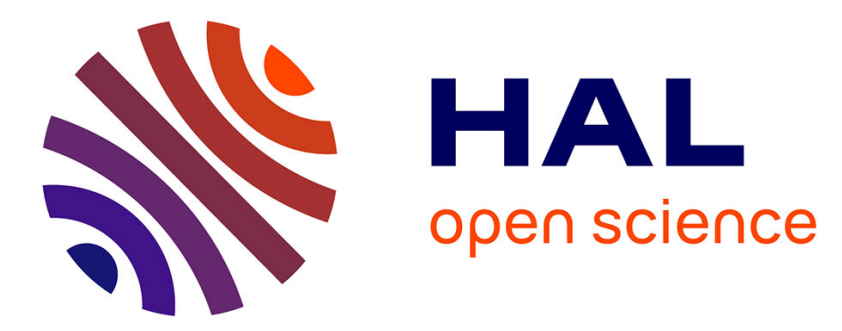

\title{
Natural enemy-mediated indirect interactions among prey species: potential for enhancing biocontrol services in agroecosystems
}

Anaïs Chailleux, Emily K Mohl, Mickaël Teixeira Alves, Gerben J Messelink, Nicolas Desneux

\section{To cite this version:}

Anaïs Chailleux, Emily K Mohl, Mickaël Teixeira Alves, Gerben J Messelink, Nicolas Desneux. Natural enemy-mediated indirect interactions among prey species: potential for enhancing biocontrol services in agroecosystems. Pest Management Science, 2014, 70 (12), pp.1769 - $1779 . \quad 10.1002 /$ ps.3916 . hal-01571388

\section{HAL Id: hal-01571388 \\ https://hal.inria.fr/hal-01571388}

Submitted on 2 Aug 2017

HAL is a multi-disciplinary open access archive for the deposit and dissemination of scientific research documents, whether they are published or not. The documents may come from teaching and research institutions in France or abroad, or from public or private research centers.
L'archive ouverte pluridisciplinaire HAL, est destinée au dépôt et à la diffusion de documents scientifiques de niveau recherche, publiés ou non, émanant des établissements d'enseignement et de recherche français ou étrangers, des laboratoires publics ou privés. 


\title{
Natural enemy-mediated indirect interactions among prey species: potential for enhancing biocontrol services in agroecosystems
}

\author{
Anaïs Chailleux, ${ }^{\mathrm{a}, \mathrm{b}, \mathrm{c}}$ Emily K Mohl, ${ }^{\mathrm{d}}$ Mickaël Teixeira Alves, ${ }^{\mathrm{a}, \mathrm{e}, \mathrm{f}}$ \\ Gerben J Messelink ${ }^{g}$ and Nicolas Desneux ${ }^{{ }^{*}}$
}

\begin{abstract}
Understanding how arthropod pests and their natural enemies interact in complex agroecosystems is essential for pest management programmes. Theory predicts that prey sharing a predator, such as a biological control agent, can indirectly reduce each other's density at equilibrium (apparent competition). From this premise, we (i) discuss the complexity of indirect interactions among pests in agroecosystems and highlight the importance of natural enemy-mediated indirect interactions other than apparent competition, (ii) outline factors that affect the nature of enemy-mediated indirect interactions in the field and (iii) identify the way to manipulate enemy-mediated interactions for biological control. We argue that there is a need to increase the link between community ecology theory and biological control to develop better agroecological methods of crop protection via conservation biological control. In conclusion, we identify (i) interventions to be chosen depending on agroecosystem characteristics and (ii) several lines of research that will improve the potential for enemy-mediated indirect interactions to be applied to biological control.
\end{abstract}

(c) 2014 Society of Chemical Industry

Keywords: apparent competition; generalist predator; pest management; conservation biological control; functional biodiversity; ecosystem services

\section{INTRODUCTION}

Indirect interactions have the potential to occur in any community of three or more interacting species, ${ }^{1,2}$ and complex interactions, including both direct and indirect effects, occur in natural and agricultural ecosystems. ${ }^{3}$ By contrast to interactions like predation and symbiosis that involve contact between species, indirect interactions occur between two species that can be separated in time or space and require at least one additional mediating species., ${ }^{4,5}$ Indirect interactions among species occur not only between trophic levels, in the form of bottom-up and top-down effects mediated through trophic cascades, ${ }^{6-10}$ but also within trophic levels via resource competition ${ }^{11}$ and/or shared predation..$^{4,12}$ In simple models, ${ }^{4}$ prey species that do not directly interact can still negatively affect each other through interactions with a shared natural enemy (NE). This phenomenon is called apparent competition, because the dynamics of the two prey resemble that of prey competing for resources. ${ }^{4}$ Indirect interactions often strongly affect food web structure, ${ }^{13}$ and such interactions can generate both short-term effects on species abundance and long-term effects on population dynamics. ${ }^{5,14,15}$

Insect NEs of agricultural pests provide key biocontrol services in agroecosystems worldwide, ${ }^{16-19}$ so NE-mediated indirect interactions have practical consequences. ${ }^{20}$ Plant- and/or natural-enemy-mediated indirect interactions between herbivores have been increasingly reported in agroecosystems. ${ }^{21-26}$ These indirect interactions between pest species may be positive or negative and symmetric or asymmetric. The net impact of NEs on pest dynamics depends on the direction, intensity and duration of direct and indirect interactions among prey and their shared NEs.

Although biological control is founded on the concept of trophic cascades, it has rarely been implemented on the basis of indirect interactions within a trophic level. However, results of many studies may be interpreted in light of NE-mediated indirect interactions. For example, high arthropod diversity has been shown to enhance NE populations, resulting in increased biocontrol services on target pests in large-scale field studies. ${ }^{27,28}$ In more focused experiments, the presence of alternative prey may increase control of pest species by generalist predators under field and semi-field

\footnotetext{
*orrespondence to: Nicolas Desneux, French National Institute for Agricultural Reseach (INRA), UMR1355-ISA, 400 route des chappes, 06903 Sophia-Antipolis, France.E-mail:nicolas.desneux@sophia.inra.fr

a French National Institute for Agricultural Reseach (INRA), UMR1355-ISA, Sophia-Antipolis, France

b InVivo AgroSolutions, Paris, France

c CIRAD, UPR HortSys, Montpellier, France

d Department of Ecology, Evolution and Behavior, University of Minnesota, Saint Paul, MN, USA

e BIOCORE, INRIA, Sophia-Antipolis, France

$f$ Department of Mathematical Sciences, University of Bath, Bath, UK

g Wageningen UR Greenhouse Horticulture, Bleiswijk, The Netherlands
} 


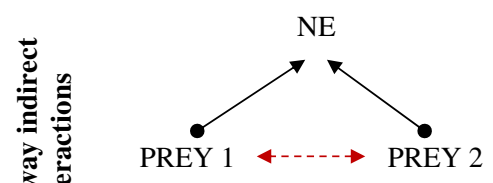

(1) Apparent mutualism $(+,+)$

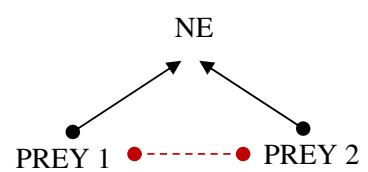

(2) Apparent competition (-,-)

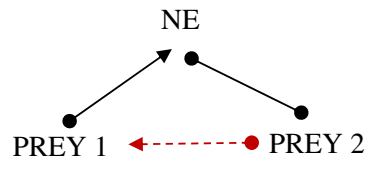

(3) Apparent predation $(+,-)$

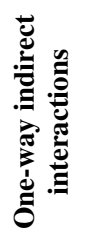

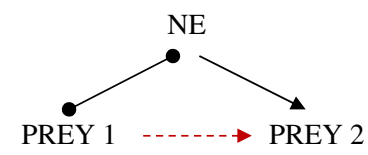

(4) Apparent commensalism $(+, 0)$

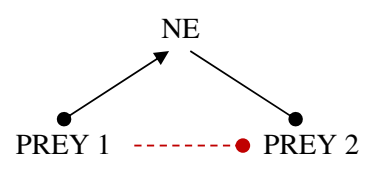

(5) Apparent amensalism (-,0)

Figure 1. Summary of types of indirect interactions between two prey species with a shared natural enemy (NE). Lines with arrows indicate a positive effect in the direction of the arrows, and lines with circles indicate negative effects in the direction of the circles. Solid lines indicate direct interactions, and dashed lines indicate NE-mediated indirect interactions.

conditions. $^{26,29-33}$ Overall, maintaining simultaneously low densities of various pests should theoretically promote the persistence of NEs through apparent competition. ${ }^{16}$ However, the presence of several pests does not always result in NE-mediated indirect interactions; ${ }^{15,34,35}$ the nature of indirect interactions primarily depends on specific species traits.

In this review, we argue that, although it is now obvious that $\mathrm{NE}$-mediated indirect interactions contribute to pest population dynamics, insufficient efforts have been made to generate predictions that would facilitate the use of indirect interactions in biological control. Integrated pest management (IPM) practitioners need sophisticated ecological tools that utilise the functional characteristics of agroecosystems to predict the sign and strength of indirect interactions. Indirect interactions are known and described, and general theories explaining indirect interaction mechanisms exist, but now we need to link pest management (via biological control) and community ecology theory. In this review we aim to establish the first links between the ecological theory of indirect interactions and the practice of pest management via biological control.

\section{THE NATURE OF INDIRECT INTERACTIONS}

\subsection{Overview}

Depending on the temporal or spatial scale, the behaviour of prey and NEs involved and the quality and density of prey (affecting NE numerical response), the NE-mediated indirect interactions can take different forms. ${ }^{36}$ Prey that interact through shared predators may have one- or two-way interactions with each other, and the effects may be either positive or negative (Fig. 1). Apparent competition $(-,-)$ and apparent mutualism $(+,+)$ are two-way indirect interactions (symmetrical interactions) that can occur between prey sharing a common NE; conversely, apparent amensalism $(-, 0)$ and apparent commensalism $(+, 0)$ are one-way indirect interactions (asymmetrical interactions) that occur when only one prey indirectly affects the other. In addition, NE-mediated apparent predation between two prey $(+,-)$ may occur, ${ }^{4,37}$ particularly when interactions are considered over different timescales (Fig. 1).

Negative indirect interactions typically occur when alternative prey increase the abundance or density of a NE (numerical response or aggregation), resulting in increased consumption of the target prey. Positive indirect interactions typically occur in the absence of a numerical response or aggregation, or through satiation and prey preference when an alternative prey reduces encounter rates between the NE and target prey. Mechanisms for one-way indirect interactions may include differences in the numerical response caused by the prey quality (see Section 2.2), important differences in population sizes of the two prey (see Section 2.3) or NE preferences ${ }^{38}$ (see Section 4.1), among others.

Empirical studies frequently do not fully test the reciprocity of the interactions between prey. ${ }^{22,36}$ For example, Muller and Godfray $^{39}$ manipulated grass aphid densities and measured the effects on out-planted nettle aphid densities, but they did not test for reciprocal effects of nettle aphids on grass aphids. However, possible asymmetry of indirect interactions (one-way) has important basic and applied implications. For biological control, it is crucial to know whether alternative prey will negatively affect the target prey population or not.

\subsection{Role of prey quality}

As described above, one of the conditions for apparent competition is the capacity of both prey species to support a numerical response of a shared NE. However, differences in the numerical response could occur, depending on the quality of the prey, ${ }^{40-42}$ and lead to one-way NE-mediated interactions. If one prey allows a numerical response of a shared NE and the other one does not, the latter species will have no effect on the former, resulting in apparent amensalism. For example, the field study of Pons et al. ${ }^{43}$ reported that some heteropteran predators do not respond numerically to Therioaphis trifolii and Aphis craccivora on alfalfa, suggesting that these species will not reciprocally interact with other prey via heteropterans.

Higher equilibrium densities of NEs through apparent competition may not be caused by increased prey availability alone, but may also result from diet mixing. It has been shown that juveniles of the predatory mite Amblyseius swirskii survive and develop better on a mixed diet of thrips and whiteflies than on a single diet of either of these species. Thus, thrips may promote control of whiteflies because diet mixing increases the predator numerical response to whiteflies without generating a reciprocal effect on thrips. ${ }^{32}$ So far, this aspect of mixed diets has been ignored in theoretical models about indirect interactions, but may be important to integrate in theoretical tools aiming to optimise biological control programmes. 


\subsection{Role of prey density}

Apparent commensalism may occur when one prey reduces predation on another one in an asymmetrical fashion, which often has negative consequences for biological control. Short-term apparent commensalism was observed in tomato crops where the mirid predator Macrolophus pygmaeus was found less effective to reduce population growth of the whitefly Bemisia tabaci in the presence of the invasive pest Tuta absoluta than when B. tabaci was alone. ${ }^{26,44}$ However, the effect appeared to be mostly one way, in that B. tabaci had a low effect on predation on T. absoluta. This study suggested that prey abundance (and related prey-predator encounter rate) or availability (exposure to predation) may favour one-way interactions (at least in the absence of marked predator aggregation, see Section 3.1). However, the outcome at larger scales (spatial and temporal) could be drastically different. ${ }^{26}$

One-way indirect interactions driven by differences in abundance across prey species appear to have a strong influence on the structure of host-parasitoid communities ${ }^{45,46}$ where two-way links in quantitative food webs are rare but one-way links from common to rare prey species are more frequent. Note that food webs are essentially observational, and experiments to test their predictions are recommended. ${ }^{15}$ However, if relative prey abundance frequently generates one-way indirect interactions, pest management programmes relying on conservation biological control may require significant action promoting alternative prey. At the same time, the impacts of alternative prey are likely to change over the short- and long-term.

\section{SHORT-TERM VERSUS LONG-TERM INTERACTIONS}

Short-term NE-mediated interactions occur faster than one NE life cycle, and long-term interactions occur over timeframes longer than one NE life cycle. Given the long generation times of many NEs relative to their prey, the original concept of apparent competition that focused on the numerical response of food-limited predators may not explain many observations about the way NEs can influence the structure of communities. In theory, both shortand long-term indirect effects of shared NEs can lead to positive and negative NE-mediated indirect interactions.

\subsection{Short-term indirect interactions}

Short-term interactions usually occur within a single generation as a result of satiation, switching behaviour and/or prey preference in the shared natural enemy. ${ }^{14,47}$ Many studies have shown reduced predation rates on a target pest in the presence of alternative prey, resulting in short-term apparent mutualism or commensalism. ${ }^{23,48-51}$ Short-term apparent mutualism occurs through a dilution of encounter rates between prey and NEs, notably when NEs settle in prey patches independently of prey density and when they show a time-limited functional response. ${ }^{52}$ Alternatively, apparent commensalism may occur at a short-term scale owing to differences in prey abundance or availability causing a one-way dilution effect; this may occur only when the NE does not aggregate on high prey density. ${ }^{53-55}$ Commensalism occurs also when a NE encounters toxic prey on a plant and departs before consuming other, palatable, prey. ${ }^{56}$

Negative interactions may also arise at short timescales. For example, alternative prey may increase NE foraging activities and/or aggregation ${ }^{57}$ (see Section 4.1). Apparent competition may be observed not only in the long-term with NEs that undergo a numerical response but also in the short-term if the NE is an optimal forager and prey are limited in number. This is because NEs will aggregate to and stay longer in a patch where there are more prey, ultimately exploiting both prey species more than if each had been alone at a lower density. ${ }^{58}$

\subsection{Long-term indirect interactions}

Even when a short-term interaction occurs between two prey, food-limited NEs should eventually cause a long-term negative indirect interaction between prey owing to the numerical response of $\mathrm{NEs} .^{26,29,32,33,59,60}$ This interaction results from the same mechanism observed when practitioners feed NEs with pollen or artificially produced eggs ${ }^{61,62}$ (see Section 5.1). Liu et al. ${ }^{30}$ reported more effective control of spider mites in apple orchards in the presence of both a predator and alternative prey than in the presence of a predator alone. The effects of the alternative prey on predator numerical response were detectable within a week of predator introductions, but differences in prey densities between treatments took more than a month to appear. Therefore, the numerical response of the predator may be observed more rapidly than the actual indirect interactions between prey.

Examples of short-term positive indirect interactions are relatively common (Section 3.1), but they have been mostly observed in studies where alternative prey were introduced into a controlled system with a limited number of predators, or where the behaviour of individual predators was measured. In such experiments, the main limitation was that the timescale of the experiments did not allow for a numerical response of the NEs. If NEs are not prey limited and exhibit satiation or switching behaviour, this can also lead to long-term apparent mutualism. ${ }^{14}$ However, empirical evidence for this is limited (but see the article of Tack et al. ${ }^{15}$ ). Long-term apparent mutualism may also occur when population densities of one prey show cycles, resulting in repeated satiation of the shared predators and repeated reduced predation on the other prey. ${ }^{63,64}$ However, further studies are needed to depict the precise nature of long-term indirect interactions in most empirical systems.

\section{FACTORS AFFECTING INDIRECT INTERACTIONS: PREDATOR AND PREY BEHAVIOURS AND SCALES OF OBSERVATION}

\subsection{The effect of predator and prey behaviours}

Predator and prey behaviours may modify the strength, the direction and the symmetry of indirect interactions. Behavioural changes in the way that two species interact through the presence of a third species are called trait-mediated indirect interactions ${ }^{34,56}$ or functional indirect interactions, ${ }^{13}$ although this last term is not widely used.

\subsubsection{Predator behaviour}

NE preference for a given prey may arise (i) from a preference for particular species characteristics or (ii) from a response to prey densities, i.e. prey switching (a predator switches prey when its relative attack rate on a given prey type increases faster than the prey's relative abundance). ${ }^{65}$ Many predators exhibit switching behaviours, ${ }^{66}$ including those studied for biological control. ${ }^{44,67-70}$ With either type of NE preference, the potential for negative indirect interactions to enhance biological control can be drastically reduced if NEs prefer the alternative prey (for predators ${ }^{23,47,71-74}$ 
and for parasitoids ${ }^{75,76}$ ). NE behaviour, when shaped by prey preferences, can induce one-way indirect interactions between prey (both apparent amensalism ${ }^{77,78}$ and apparent commensalism ${ }^{56}$ ), sometimes favouring the pest. Predator preference is primarily determined by prey behavioural and physiological characteristics, such as (i) prey nutritive quality, ${ }^{35,73,79,80}$ (ii) prey size or patch size, $^{81}$ (iii) prey mobility ${ }^{23,34,74,82}$ or (iv) herbivore-induced plant volatiles..$^{83-85}$

\subsubsection{Prey behaviour}

Prey behaviour is a major factor that modulates NE-mediated indirect interactions among prey, notably in the short term. Indeed, prey can display various behaviours to avoid predation or parasitism, including settling in physical refuges, ${ }^{86-90}$ fleeing a patch showing high predator density ${ }^{57,91}$ and adopting defensive behaviours. ${ }^{92-94}$ These behaviours can reduce encounter rates with predators and may ultimately lead to apparent amensalism, or even apparent predation, if the alternative prey remains available to the predators in the system.

\subsection{Spatial scale of observation}

The way NEs perceive the spatial distribution of shared prey can affect the predicted outcome of indirect interactions. ${ }^{12}$ Experimental and observational studies of the effects of alternative food sources on biological control have occurred at a variety of scales, ranging from petri dishes to landscape-level manipulations. Perhaps not surprisingly given the complex nature of many indirect interactions, the spatial scale of the manipulation often appears to affect the nature of the indirect interactions observed. ${ }^{15,95}$ For example, Ostman and Ives ${ }^{96}$ found predator aggregation to aphids, but not planthoppers, in field studies, consistent with short-term apparent amensalism. However, they found short-term apparent commensalism in cage studies, where predators spent time on plants with pea aphids and neglected plants with potato leafhoppers.

\section{APPLIED STRATEGIES}

\subsection{Alternative prey for early-season establishment}

Alternative prey can help natural enemy populations establish in crops before pest arrival, notably early in the season. Temporal dissociation between natural enemy and pest arrival in crops can result in high NE densities relative to the density of the invading pest, thus preventing or delaying pest outbreaks. ${ }^{97,98}$ For example, corn leaf aphids usually arrive early in the season on sorghum, and they support early population growth of coccinellids that control economically damaging greenbugs later in the season. ${ }^{99,100}$ In addition, when a targeted pest does not enable strong NE numerical response, NE population growth before pest arrival may increase the strength of biocontrol (see Section 2.2). Yoo and $\mathrm{O}^{\prime} \mathrm{Neil}^{101}$ reported that the predator $O$. insidiosus showed a numerical response to thrips (alternative prey) but not to the aphid pest in soybean fields. However, thrips promote high predator densities early in the season that may reduce aphid populations later in the season..$^{98}$

Introducing alternative prey early in the season could be a method to increase biological control by inducing apparent amensalism or apparent competition against a targeted pest..$^{30,102}$ In greenhouse crops, the manipulation of NE indirect interaction is easier because biotic and abiotic factors are better controlled than in open fields. This probably explains why temporal one-way indirect interactions are already used on occasion to enhance biological control in greenhouses. The 'alternative host and parasitoid in first' method involves introducing non-pest hosts on non-crop plants to maintain parasitoid populations in greenhouses where crops are going to be planted. If a targeted pest infests the crop, parasitoids can spill over from non-crop plants and parasitise target pest populations..$^{28,103-105}$ Similarly, the alternative prey can be replaced by an alternative food source; for example, sterilised Ephestia kuehniella eggs are used to promote mirid predator population growth in tomato crops early in the season. ${ }^{62}$ However, this is not strictly a NE-mediated indirect interaction, as one of the 'prey' shows artificial population dynamics. Overall, these methods used in greenhouses generate the same patterns observed naturally in some fields: alternative prey or food sources promote NE population growth prior to pest outbreaks and increase biocontrol services.

\subsection{Alternative prey to sustain natural enemies during low-pest-density periods}

When alternative prey and pests do not co-occur in the habitat at a given time of the season, they can still interact indirectly at longer temporal scales (Fig. 2). Some predators require the presence of alternative prey in order to survive (or even develop, e.g. moulting) during periods when the target pest is absent. ${ }^{106}$ Therefore, temporal separation between the pest and alternative prey may be helpful for biological control. This is particularly important in annual crops because the entire ecosystem is regularly disturbed. The availability of alternative prey in neighbouring habitats during non-cropping periods can maintain the predator population from one year to another. In addition, many generalist predators attack prey both on plants and on the ground. This broad diet enables predators to survive in fields on bare soils during
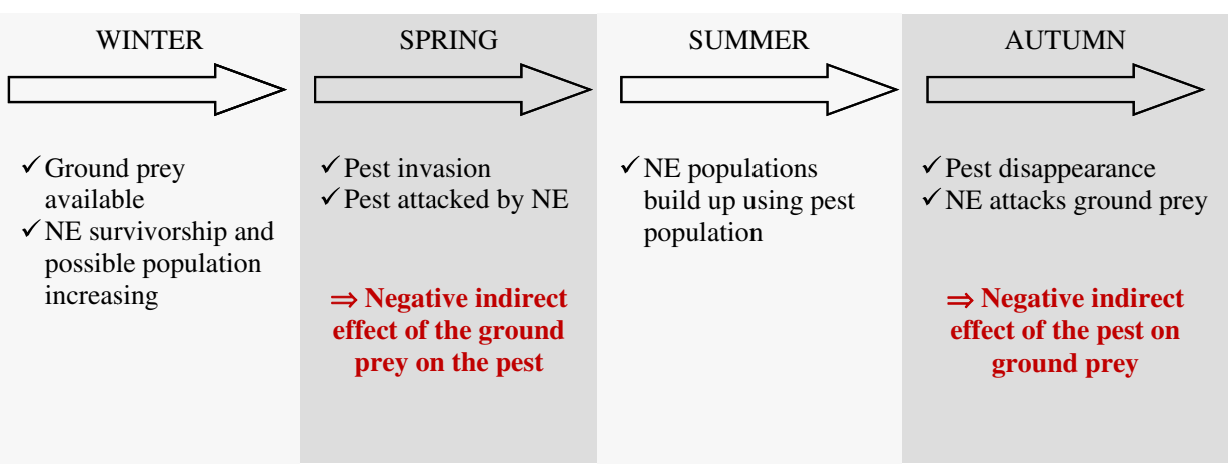

Figure 2. Example of possible mechanisms of apparent competition $(-,-)$ between pest and alternative prey at the scale of 1 year in annual crops. 
non-cropping periods and may ensure that they are present at the beginning of new cropping seasons. For example, predatory beetles survive from autumn until spring by feeding on lumbricid and collembolan prey in spelt ${ }^{107}$ and spiders feeding on ground invertebrates in rice. ${ }^{27,108}$ This suggests that soil and tillage practices that maintain alternative prey for NEs can benefit NE-mediated indirect interactions. ${ }^{109}$

Similarly, in perennial crops, like orchards, pests may not be available during particular periods of the season owing to pest and/or crop phenology. ${ }^{110}$ The NEs may rely on alternative prey to sustain them during the non-pest periods of the year. For example, biological control of psyllids in pistachio crops in Turkey relies primarily on apparent competition with the leaf-curling aphid on almond trees, mediated by the predatory bug Anthocoris minki. ${ }^{111}$ The leaf-curling aphid is a key alternative prey for the predator when pistachio psyllids are not available on pistachio trees in early spring. Similar findings have been reported for parasitoids of grape leafhoppers that diapause on alternative winter hosts on Prunus and Rubus plants during the winter in California. ${ }^{112-114}$

\subsection{Alternative and target prey concurrently present in the agroecosystem}

When alternative and target prey concurrently interact, the outcomes of NE-mediated indirect interactions are more variable and harder to predict than they are when there is temporal dissociation between prey, in part because behaviour and other traits become more important (see Sections 2.2 and 4.1).

The spatial location of the two prey species may reduce the efficiency of negative indirect interactions. This is especially likely when the alternative prey is provided in or near crops using external subsidies like mulch or banker plants. Mulch may increase the availability of detritivores for omnivorous predators, resulting in improved biocontrol of herbivores on crops. ${ }^{115}$ However, strategies to increase alternative prey densities do not always improve herbivore suppression. For example, alternative prey in mulch may draw predators away from pests in the plant canopy. ${ }^{116,117}$

With concurrent prey, NE preference may also modulate the outcome of NE-mediated indirect interactions (Section 4.1). Consequently, strategies relying on indirect interactions between co-occurring prey for biological control will require intimate knowledge of the species involved and clearly defined objectives. For example, it will be important to ask whether long-term or short-term effects are desired, and if a long-term effect is sought, whether a short-term mutualism or commensalism is acceptable for the producer? An alternative to developing plans that require such detailed knowledge is to increase agroecosystem biodiversity overall in the hope of improving ecosystem services. Indeed, NE-mediated indirect interactions are one of the mechanisms involved in the concept of 'functional biodiversity'. ${ }^{118,119}$

\section{PREY EXCLUSION MEDIATED BY SHARED NATURAL ENEMIES}

Apparent competition may affect prey population dynamics in the same way as resource competition, ${ }^{120}$ and prey exclusion is a possible outcome if (i) predation is very high on one prey (overexploitation), (ii) there are no refuges for the prey that support the smallest NE population or (iii) the less competitive prey suffers other detrimental interactions, such as resource competition. ${ }^{12}$

The presence of a prey species that supports high NE densities may promote overexploitation and potential exclusion of alternative prey. Exclusion via apparent amensalism has been demonstrated empirically in a long-term population study in which prey species were not allowed to compete directly for resources. ${ }^{60}$ Apparent competition could also theoretically lead to prey exclusion through destabilisation of the ecosystem; the introduction of a second prey species may increase overall availability of prey for an NE. Called the paradox of enrichment, ${ }^{121}$ an increase in abundance of prey could favour NE-prey oscillations and may lead to prey extinction. However this phenomenon is rarely observed in ecosystems when both prey species are edible because either (i) the NE population density has a negative effect on its own per capita population growth rate via mechanisms other than prey depletion or (ii) a class of prey individuals shows low vulnerability to NEs. ${ }^{122}$ The potential for prey exclusion via indirect interactions has important implications in the field of biological control but also in conservation biology. The possible impacts of indirect interactions on prey coexistence have been reviewed thoroughly in the field of conservation biology. ${ }^{123}$ Notably, the authors stressed the negative role of one-way indirect interactions in endangered species conservation, and this may also be a risk when predators spill over from agroecosystems into smaller patches of native habitat. By contrast, possible pest exclusion through NE-mediated apparent competition (or other indirect interactions) has been rarely documented for biological control purposes. ${ }^{45,124}$ Parasitoid-mediated apparent amensalism between two planthopper species excluded populations of one species more frequently than when populations were not exposed to apparent amensalism. ${ }^{124}$ The hypothesis that apparent competition can lead to pest exclusion in agroecosystems has never been clearly demonstrated and deserves more attention from experimental field ecologists. However, even in the absence of complete exclusion, biological control may still be effectively achieved, and NE persistence in the agroecosystem improved.

\section{NATURAL ENEMY INDIRECT INTERACTION VIA HIGHER-ORDER PREDATORS: RISKS AND POTENTIAL PITFALLS}

Higher-order predation may intersect with apparent competition, so we briefly discuss how it can affect biological control in light of NE-mediated indirect interactions between prey. Cannibalism is defined as predation of conspecifics, hyperpredation is typically defined as NEs attacking other NEs without sharing prey and intraguild predation (IGP) is defined as predation by one species on interspecific competitors, which are designated as intermediate-order NEs. Hereafter, the term higher-order predation (HO predation) will be used to refer to both IGP and hyperpredation. ${ }^{8} \mathrm{HO}$ predators are relatively frequent in agroecosystems. ${ }^{125,126}$ However, most higher-order NEs feed on intermediate-order NEs only when other prey are rare, ${ }^{127}$ reducing the potential for $\mathrm{HO}$ predation to disrupt biocontrol services. ${ }^{128}$ Additionally, most generalist predators are cannibalistic. Therefore, ecosystems with only one NE and one prey may include two prey types: conspecific and heterospecific prey. The effect of prey availability on cannibalism is particularly well documented in spider species. ${ }^{82,129-131}$ As with $\mathrm{HO}$ predation, cannibalism decreases with the abundance of other heterospecific prey.

Over long timescales, juveniles (conspecific prey) or HO prey may generate a numerical response (or the survival) of the $\mathrm{HO}$ predators when primary prey are rare, ultimately negatively affecting the pests (apparent amensalism or apparent competition) 


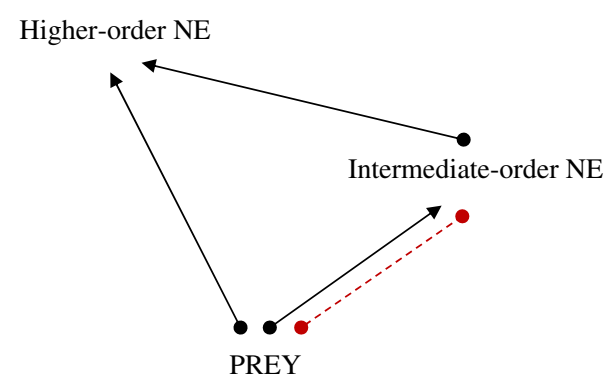

Figure 3. Indirect interactions involving a NE as prey through higher-order predation. Shown is an example of apparent competition between the target prey and the intermediate-order NE (intraguild prey) when sharing a higher-order NE. Lines with arrows indicate a positive effect in the direction of the arrows, and lines with circles indicate negative effects in the direction of the circles. Solid lines indicate direct interactions, and dashed lines indicate NE-mediated indirect interactions.

(see Fig. 3) and improving biological control. ${ }^{132}$ However, HO predation and cannibalism can reduce the impact of predation on prey in arthropod communities because of suppression of the intermediate-order NEs (the HO prey and juveniles). ${ }^{25,71,133,134}$ Such reduction may occur in spite of possible adaptive behaviours exhibited by $\mathrm{HO}$ prey/juveniles to avoid attack because such adaptive behaviours ultimately distract them from attacking their prey. ${ }^{135,136}$ However, overall, the potential risk of HO predation disrupting biological control is thought to be relatively low. ${ }^{137-139}$ Thus, cannibalism and $\mathrm{HO}$ predation could be expected to disrupt the efficiency of the HO prey/juveniles without a significant reduction in overall biological control services compared with those from a single NE alone. Moreover, $\mathrm{HO}$ predation may sustain NE populations over the long term when target prey populations are rare.

Finally, we can note that apparent competition may occur between two natural enemies via a hyperpredator. The existence of such interactions has been rarely studied (we found only one laboratory study ${ }^{140}$ ), even though many $\mathrm{HO}$ predators are known to prey on several NE species. ${ }^{25,127}$

\section{MODELLING APPLICATIONS}

Holt ${ }^{4}$ described indirect effects in one-predator-two-prey systems using basic Lotka-Volterra types of model, and suggested the terminology of apparent competition. By modifying the assumptions about species behaviour and environmental conditions implicit in Holt's model, ${ }^{4}$ a number of authors have explored a wide range of mechanisms that may alter the nature of indirect interactions. ${ }^{20}$ Studies have investigated the impacts of saturating functional and numerical responses ${ }^{14,63,141-146}$ (see Section 2.2), prey and predator behaviour ${ }^{14,147-153}$ (see Section 4.1), spatial heterogeneity ${ }^{12,57,91,154}$ (see Section 4.2), varying timescales ${ }^{57,155}$ (see Section 3) and interference. ${ }^{14,146}$ Many of these theoretical studies have predicted novel impacts of shared predation or have provided insight into potential biological mechanisms for patterns that could not have been detected or had been overlooked by empirical approaches.

However, these separate models fail to provide a unified theory that could easily be applied to a wide range of biological systems. One framework that holds potential to fill this gap is based on community modules, ${ }^{156,157}$ which posit that multispecies communities can be described by an extension of pairwise interactions. These modules actually correspond to general patterns of interactions within more complex systems composed of multiple trophic levels and interactions.

For instance, when simple rules can be derived in community modules, such as the $R^{*}$ and the $P^{*}$ rules (which predict that the competitor that can persist at the lowest resource level excludes the other) in the shared resource and shared predation modules respectively, ${ }^{11,120,158}$ these allow for fundamental predictions about species dominance and indirect interactions. These rules are generated by comparing species equilibria in models that include or exclude an additional prey species, which is analogous to the way indirect effects are investigated in empirical studies. ${ }^{36}$ However, their scope of application is currently limited: they are designed for extremely simple community models, which overlook most of the behavioural, temporal and spatial mechanisms influencing interactions and affecting predictions. Considering the substantial support that such rules could provide for optimising biological control programmes, significant tasks for future theoretical and empirical studies are (1) to develop key rules derived from community modules and (2) to identify critical assumptions underlying models of community interactions. The goal is to develop predictions for more complicated communities on the basis of simple variables, such as the relative abundance of prey species, their phenology and predator functional and numerical responses.

\section{CONCLUSION AND PERSPECTIVES}

Understanding how pests, alternative prey and NEs interact in complex and heavily managed environments such as agroecosystems is essential to the development of environmentally sound pest management methods in agriculture. ${ }^{19,159,160}$ The current literature about NE-mediated indirect interactions among arthropods demonstrates that such interactions (i) are very frequent in agroecosystems and (ii) have a strong effect on pest, prey and NE population dynamics. Most indirect interactions appear to be one-way interactions. However, the reciprocity of indirect interactions has rarely been tested, as biological control-related studies are often most interested in one-way interactions, and it is more challenging to implement fully informative experimental designs. Additionally, positive indirect interactions are most likely to occur over short timescales, whereas negative indirect interactions often require longer timeframes to allow for a numerical response of the NE. Nevertheless, certain NE foraging behaviours, such as aggregation to sites of high host density, may generate negative interactions in the short term.

In agroecosystems, in contrast to natural ecosystems, crop management techniques (e.g. mixed crops, banker plants, cover crops, etc.) strongly influence the type and strength of NE-mediated indirect interactions. Habitat management may not always demand a radical change in farming practices ${ }^{161}$ and could be used to manipulate NE-mediated interaction. We summarise in Table 1 the agroecosystem characteristics and the corresponding practices that can influence NE-mediated indirect interactions in managed agricultural ecosystems. Importantly, biological control may often benefit from indirect interactions that account for temporal variability in pest abundance, but outcomes are more variable when alternative prey coexist and share predators with pests at the same time.

We claim that a strong link should be created between community ecology theory and IPM practices to allow practitioners to use 
Table 1. Summary of potential human interventions to enhance biological control, and their consequent effects on NE-mediated interactions, in relation to ecosystem item characteristics

\begin{tabular}{|c|c|c|c|}
\hline & Item characteristics & Potential interventions & Effects on NE-mediated interactions \\
\hline \multirow[t]{3}{*}{ Plants } & $\begin{array}{l}\text { Presence of plant-provided } \\
\text { food }\end{array}$ & & $\begin{array}{l}\text { Enhanced NE survival and } \\
\text { numerical response }\end{array}$ \\
\hline & Presence of prey refuges & Plant cultivar choice & $\begin{array}{l}\text { Sustains food sources for the } \\
\text { NE }\end{array}$ \\
\hline & $\begin{array}{l}\text { Plant cultivars releasing } \\
\text { volatiles in response to } \\
\text { herbivores }\end{array}$ & $\begin{array}{l}\text { Releasing NE trained to } \\
\text { respond to } \\
\text { herbivore-induced plant } \\
\text { volatiles }\end{array}$ & Enhanced the NE efficacy \\
\hline \multirow[t]{4}{*}{ Natural enemies } & Behaviour (prey preference) & Choice of NE to release & Enhanced NE efficiency \\
\hline & Numerical response & Addition of artificial food & Increased NE density \\
\hline & Higher-order NE & Choice of NE to release & $\begin{array}{l}\text { Limited negative } \\
\text { interactions between NEs }\end{array}$ \\
\hline & Nutritious value & $\begin{array}{l}\text { Adding banker plants } \\
\text { attracting high-quality } \\
\text { prey }\end{array}$ & $\begin{array}{l}\text { Enhanced NE numerical } \\
\text { response }\end{array}$ \\
\hline \multirow[t]{2}{*}{ Prey } & Phenology & $\begin{array}{l}\text { Introducing alternative prey } \\
\text { prior to pest arrival }\end{array}$ & \\
\hline & Behaviour & $\begin{array}{l}\text { Adding plant species that } \\
\text { are repellent to herbivores }\end{array}$ & $\begin{array}{l}\text { Negative (reduced prey host } \\
\text { availability) or positive } \\
\text { (maximised predation on } \\
\text { fewer pests) effects }\end{array}$ \\
\hline \multirow[t]{6}{*}{ Agroecosystem } & Plant diversity & Adding banker plants & $\begin{array}{l}\text { Enhance prey diversity for } \\
\text { the NE }\end{array}$ \\
\hline & & Adding intercropping & \\
\hline & & Mixing crop & \\
\hline & Soil fauna & $\begin{array}{l}\text { Soil practice choice: } \\
\text { no-tillage practices }\end{array}$ & \\
\hline & Perennial crop & Adding intercropping & \\
\hline & Annual crop & Adding cover crop & \\
\hline
\end{tabular}

indirect interactions, especially apparent competition and apparent amensalism, to improve crop protection. Similarly to the development of pest thresholds for insecticide use, we argue for the development of practical tools that define the conditions under which indirect interactions can be beneficial, and which actions should be carried out by practitioners. Applied models, as already used for pesticides in IPM programmes, will be an essential tool to integrate indirect interaction manipulations into IPM programmes (e.g. see Section 8).

Our review highlights some initial conditions and possibilities for using indirect interactions to enhance biological control. Firstly, indirect interactions may rarely lead to pest suppression; therefore, they could not be used to control disease vectors in crops. Secondly, indirect interactions are more likely to occur in a diversified environment but will be easier to manipulate in a controlled agroecosystem; thus, manipulation is more likely to occur via an increase in the general biodiversity in open field and via precise manipulations in protected crops. Additionally, the use of NE-mediated indirect interactions is easiest when there is a temporal dissociation between the two prey (see Sections 5.1 and 5.2), so this should be the first approach for developing applied strategies. Because crop combinations at a field or regional scale have the potential to affect indirect interactions, another research priority should be to identify crops that do not share pests but that support pests that share natural enemies (see Sections 3.2 and 5.3). Finally, attempts to choose banker plants or cover crops to facilitate alternative prey in agroecosystems should include three main criteria: (1) the alternative prey is not a pest for the crop; (2) the alternative prey supports predator reproduction; (3) in the case of simultaneous presence, the alternative prey is less preferred by the predator than the targeted pest (see Sections 4.1 and 5.3). These approaches should provide initial recommendations to help practitioners use NE-mediated indirect interactions to improve crop protection.

\section{ACKNOWLEDGEMENTS}

The authors wish to thank ANRT and InVivo Agrosolutions for funding to AC (PhD fellowship) and ND, and the Plant Health and Environment Department and the Environment and Agronomy Department of INRA and the French Ministry of Agriculture for funding to ND (CASDAR project 10063).

\section{REFERENCES}

1 Holt RD and Lawton $\mathrm{JH}$, The ecological consequences of shared natural enemies. Annu Rev Ecol Syst 25:495-520 (1994).

2 Wootton JT, Indirect effects in complex ecosystems: recent progress and future challenges. J Sea Res 48:157-172 (2002).

3 Morin P, Community Ecology. Blackwell Science, London, UK, 432 pp. (1999).

4 Holt RD, Predation, apparent competition, and the structure of prey communities. Theor Popul Biol 2:197-129 (1977).

5 Wootton JT, The nature and consequences of indirect effects in ecological communities. Annu Rev Ecol Syst 25:443-466 (1994).

6 Paine RT, Food webs - linkage, interaction strength and community infrastructure - the 3rd Tansley lecture. J Anim Ecol 49:667-685 (1980).

7 Silander JA and Antonovics J, Analysis of interspecific interactions in a coastal plant community - a perturbation approach. Nature 298:557-560 (1982). 
8 Rosenheim JA, Higher-order predators and the regulation of insect herbivore populations. Annu Rev Entomol 43:421-447 (1998).

9 Polis GA, Sears ALW, Huxel GR, Strong DR and Maron J, When is a trophic cascade a trophic cascade? Trends Ecol Evol 15:473-475 (2000).

10 Schmidt-Entling $\mathrm{MH}$ and Siegenthaler E, Herbivore release through cascading risk effects. Biol Lett 5:773-776 (2009).

11 Tilman D, Resource competition and community structure. Monographs in Population Biology, Vol. 17. Princeton University Press, Princeton, NJ, 296 pp. (1982).

12 Holt RD, Spatial heterogeneity, indirect interactions, and the coexistence of prey species. Am Nat 124:377-406 (1984).

13 Janssen A, Pallini A, Venzon M and Sabelis MW, Behaviour and indirect interactions in food webs of plant-inhabiting arthropods. Exp Appl Acarol 22:497-521 (1998)

14 Abrams PA and Matsuda $\mathrm{H}$, Positive indirect effects between prey species that share predators. Ecology 77:610-616 (1996).

15 Tack AJM, Gripenberg S and Roslin T, Can we predict indirect interactions from quantitative food webs? An experimental approach J Anim Ecol 80:108-118 (2011).

16 Symondson WOC, Sunderland KD and Greenstone MH, Can generalist predators be effective biocontrol agents? Annu Rev Entomol 47:561-594 (2002).

17 De Bach P, Biological Control of Insect Pests and Weeds. Chapman and Hall, London, UK, 844 pp. (1964).

18 Van Lenteren JC, The state of commercial augmentative biological control: plenty of natural enemies, but a frustrating lack of uptake. BioControl 57:1-20 (2012).

19 Lu YH, Wu KM, Jiang YY, Guo YY and Desneux N, Widespread adoption of $B t$ cotton and insecticide decrease promotes biocontrol services. Nature 487:362-365 (2012).

20 Harmon JP and Andow DA, Indirect effects between shared prey: predictions for biological control. Biocontrol 49:605-626 (2004).

21 Stout MJ, Thaler JS and Thomma BP, Plant-mediated interactions between pathogenic microorganisms and herbivorous arthropods. Annu Rev Entomol 51:663-689 (2006).

22 Van Veen FJF, Morris RJ and Godfray HCJ, Apparent competition, quantitative food webs, and the structure of phytophagous insect communities. Annu Rev Entomol 51:187-208 (2006).

23 Desneux $\mathrm{N}$ and O'Neil RJ, Potential of an alternative prey to disrupt predation of the generalist predator, Orius insidiosus, on the pest aphid, Aphis glycines, via short-term indirect interactions. Bull Entomol Res 98:631-639 (2008).

24 Mouttet R, Bearez P, Thomas C and Desneux N, Phytophagous arthropods and a pathogen sharing a host plant: evidence for indirect plant-mediated interactions. PLOS ONE 6:e18840 (2011).

25 Messelink GJ, Sabelis MW and Janssen A, Generalist predators, food web complexities and biological pest control in greenhouse crops, in Integrated Pest Management and Pest Control - Current and Future Tactics 1, ed. by Larramendy ML and Soloneski S. InTech, Rijeka, Croatia, pp. 91-214 (2012).

26 Bompard A, Jaworski CC, Bearez P and Desneux N, Sharing a predator: can an invasive alien pest affect the predation on a local pest? Popul Ecol 55:433-440 (2013).

27 Settle WH, Ariawan H, Astuti ET, Cahyana W, Hakim AL, Hindayana D et al., Managing tropical rice pests through conservation of generalist natural enemies and alternative prey. Ecology 77:1975-1988 (1996).

28 Huang NX, Enkegaard A, Osborne LS, Ramakers PMJ, Messelink GJ, Pijnakker J et al., The banker plant method in biological control. Crit Rev Plant Sci 30:259-278 (2011).

29 Hanna R, Wilson LT, Zalom FG and Flaherty DL, Effects of predation and competition on the population dynamics of Tetranychus pacificus on grapevines. J Appl Ecol 34:878-888 (1997).

30 Liu CZ, Yan L, Li HR and Wang G, Effects of enemy-mediated apparent competition on the population dynamics of Tetranychus urticae on apples. Biocontrol 51:453-463 (2006).

31 Harwood JD, Desneux N, Yoo HYS, Rowley D, Greenstone MH, Obrycki $\mathrm{JJ}$ et al., Tracking the role of alternative prey in soybean aphid predation by Orius insidiosus: a molecular approach. Mol Ecol 16:4390-4400 (2007).

32 Messelink GJ, van Maanen R, van Steenpaal SEF and Janssen A, Biological control of thrips and whiteflies by a shared predator: two pests are better than one. Biol Control 44:372-379 (2008).

33 Messelink GJ, Van Maanen R, Van Holstein-Saj R, Sabelis MW and Janssen A, Pest species diversity enhances control of spider mites and whiteflies by a generalist phytoseiid predator. Biocontrol 55:387-398 (2010).

34 Prasad RP and Snyder WE, Diverse trait-mediated interactions in a multi-predator, multi-prey community. Ecology 87:1131-1137 (2006).

35 Kuusk A and Ekbom B, Lycosid spiders and alternative food: feeding behavior and implications for biological control. Biol Control 55:20-26 (2010).

36 Chaneton EJ and Bonsall MB, Enemy-mediated apparent competition: empirical patterns and the evidence. Oikos 88:380-394 (2000).

37 Menge BA, Indirect effects in marine rocky intertidal interaction webs: patterns and importance. Ecol Monogr 65:21-74 (1995).

38 Meisner M, Harmon JP and Ives AR, Presence of an unsuitable host diminishes the competitive superiority of an insect parasitoid: a distraction effect. Popul Ecol 49:347-355 (2007).

39 Muller CB and Godfray HCJ, Apparent competition between two aphid species. J Anim Ecol 66:57-64 (1997).

40 Foglar $\mathrm{H}$, Malausa JC and Wajnberg E, The functional response and preference of Macrolophus caliginosus (Heteroptera: Miridae) for two of its prey: Myzus persicae and Tetranychus urticae. Entomophaga 35:465-474 (1990).

41 Hamdan AJS, Functional and numerical responses of the predatory bug Macrolophus caliginosus Wagner fed on different densities of eggs of the greenhouse whitefly, Trialeurodes vaporariorum (Westwood). J Biol Res 6:147-154 (2006).

42 Seagraves MP and Lundgren JG, Oviposition response by Orius insidiosus (Hemiptera: Anthocoridae) to plant quality and prey availability. Biol Control 55:174-177 (2010).

43 Pons X, Lumbierres B and Albajes R, Heteropterans as aphid predators in inter-mountain alfalfa. Eur J Entomol 106:369-378 (2009).

44 Jaworski CC, Bompard A, Genies L, Amiens-Desneux E and Desneux $\mathrm{N}$, Preference and prey switching in a generalist predator attacking local and invasive alien pests. PLOS ONE 8(12):e82231 (2013).

45 Muller CB, Adriaanse ICT, Belshaw R and Godfray HCJ, The structure of an aphid-parasitoid community. J Anim Ecol 68:346-370 (1999).

46 Valladares G, Salvo A and Godfray H, Quantitative food webs of dipteran leafminers and their parasitoids in Argentina. Ecol Res 16:925-939 (2001).

47 Murdoch WW, Switching in general predators: experiments on predator specificity and the stability of prey populations. Ecol Monogr 39:335-354 (1969).

48 Koss AM and Snyder WE, Alternative prey disrupt biocontrol by a guild of generalist predators. Biol Control 32:243-251 (2005).

49 Madsen M, Terkildsen S and Toft S, Microcosm studies on control of aphids by generalist arthropod predators: effects of alternative prey. Biocontrol 49:483-504 (2004).

50 Symondson WOC, Cesarini S, Dodd PW, Harper GL, Bruford MW, Glen DM et al., Biodiversity vs. biocontrol: positive and negative effects of alternative prey on control of slugs by carabid beetles. Bull Entomol Res 96:637-645 (2006).

$51 \mathrm{Xu} \mathrm{XO}$, Borgemeister $\mathrm{C}$ and Poehling HM, Interactions in the biological control of western flower thrips Frankliniella occidentalis (Pergande) and two-spotted spider mite Tetranychus urticae Koch by the predatory bug Orius insidiosus Say on beans. Biol Control 36:57-64 (2006).

52 Van Maanen R, Messelink GJ, van Holstein-Saj R, Sabelis MW and Janssen A, Prey temporarily escape from predation in the presence of a second prey species. Ecol Entomol 37:529-535 (2012).

53 Bergeson EF and Messina J, Resource- versus enemy-mediated interactions between cereal aphids (Homoptera: Aphididae) on a common host plant. Ann Entomol Soc Am 90:425-432 (1997).

54 Bergeson EF and Messina J, Effect of a co-occurring aphid on the susceptibility of the Russian wheat aphid to lacewing predators. Entomol Exp Applic 87:103-108 (1998).

55 Van Nouhuys $\mathrm{S}$ and Kraft TS, Indirect interaction between butterfly species mediated by a shared pupal parasitoid. Popul Ecol 54:251-260 (2012).

56 Van Veen FJF, Brandon CE and Godfray HCJ, A positive trait-mediated indirect effect involving the natural enemies of competing herbivores. Oecologia 160:195-205 (2009).

57 Holt RD and Kotler BP, Short-term apparent competition. Am Nat 130:412-430 (1987).

58 Evans EW and Toler TR, Aggregation of polyphagous predators in response to multiple prey: ladybirds (Coleoptera: Coccinellidae) foraging in alfalfa. Popul Ecol 49:29-36 (2007). 
59 Karban R, Hougeneitzmann D and Englishloeb G, Enemy-mediated apparent competition between two herbivores that feed on grapevines. Oecologia 97:508-511 (1994).

60 Bonsall MB and Hassell MP, Apparent competition structures ecological assemblages. Nature 388:371-373 (1997).

61 Nomikou M, Sabelis MW and Janssen A, Pollen subsidies promote whitefly control through the numerical response of predatory mites. Biocontrol 55:253-260 (2010).

62 Calvo FJ, Lorente MJ, Stansly PA and Belda JE, Preplant release of Nesidiocoris tenuis and supplementary tactics for control of Tuta absoluta and Bemisa tabaci in greenhouse tomato. Entomol Exp Applic 143:111-119 (2012).

63 Abrams PA, Holt RD and Roth JD, Apparent competition or apparent mutualism? Shared predation when population cycles. Ecology 79:201-212 (1998).

64 Brassil CE, Can environmental variation generate positive indirect effects in a model of shared predation? Am Nat 167:43-54 (2006).

65 Murdoch WW and Oaten A, Predation and population stability. Adv Ecol Res 9:1-131 (1975).

66 Sundell J, Eccard JA, Tiilikainen $\mathrm{R}$ and Ylonen $\mathrm{H}$, Predation rate, prey preference and predator switching: experiments on voles and weasels. Oikos 101:615-623 (2003).

67 Enkegaard A, Brodsgaard HF and Hansen DL, Macrolophus caliginosus: functional response to whiteflies and preference and switching capacity between whiteflies and spider mites. Entomol Exp Applic 101:81-88 (2001).

68 Chow A, Chau A and Heinz KM, Compatibility of Orius insidiosus (Hemiptera: Anthocoridae) with Amblyseius (Iphiseius) degenerans (Acari: Phytoseiidae) for control of Frankliniella occidentalis (Thysanoptera: Thripidae) on greenhouse roses. Biol Control 44:259-270 (2008)

69 Chow A, Chau A and Heinz KM, Compatibility of Amblyseius (Typhlodromips) swirskii (Athias-Henriot) (Acari: Phytoseiidae) and Orius insidiosus (Hemiptera: Anthocoridae) for biological control of Frankliniella occidentalis (Thysanoptera: Thripidae) on roses. Biol Control 53:188-196 (2010).

70 Saha N, Aditya G, Saha GK and Hampton SE, Opportunistic foraging by heteropteran mosquito predators. Aquat Ecol 44:167-176 (2010).

71 Rosenheim JA, Wilhoit LR and Armer CA, Influence of intraguild predation among generalist insect predators on the suppression of an herbivore population. Oecologia 96:439-449 (1993).

72 Eubanks MD and Denno RF, Health food versus fast food: the effects of prey quality and mobility on prey selection by a generalist predator and indirect interactions among prey species. Ecol Entomol 25:140-146 (2000).

73 Meyling NV, Enkegaard A and Brodsgaard H, Two Anthocoris bugs as predators of glasshouse aphids - voracity and prey preference. Entomol Exp Applic 108:59-70 (2003).

74 Reitz SR, Funderburk JE and Waring SM, Differential predation by the generalist predator Orius insidiosus on congeneric species of thrips that vary in size and behavior. Entomol Exp Applic 119:179-188 (2006).

75 Yokomi RK and Tang YQ, Host preference and suitability of two aphelinid parasitoids (Hymenoptera, Aphelinidae) for aphids (Homoptera, Aphididae) on citrus. J Econ Entomol 88:840-845 (1995).

76 Van Driesche RG, Nunn C, Kreke N, Goldstein B and Benson J, Laboratory and field host preferences of introduced Cotesia spp. parasitoids (Hymenoptera: Braconidae) between native and invasive pieris butterflies. Biol Control 28:214-221 (2003).

77 Settle WH and Wilson LT, Invasion by the variegated leafhopper and biotic interactions - parasitism, competition, and apparent competition. Ecology 71:1461-1470 (1990).

78 Sakata H, Density-dependent predation of the ant Lasius niger (Hymenoptera: Formicidae) on two attended aphids Lachnus tropicalis and Myzocallis kuricola (Homoptera: Aphididae). Res Popul Ecol 37:159-164 (1995).

79 Mayntz D, Raubenheimer D, Salomon M, Toft S and Simpson SJ, Nutrient-specific foraging in invertebrate predators. Science 307:111-113 (2005)

80 Korenko $\mathrm{S}$ and Pekar $\mathrm{S}$, Is there intraguild predation between winter-active spiders (Araneae) on apple tree bark? Biol Control 54:206-212 (2010)
81 Venzon M, Janssen A and Sabelis MW, Prey preference and reproductive success of the generalist predator Orius laevigatus. Oikos 97:116-124 (2002).

82 Rickers S and Scheu S, Cannibalism in Pardosa palustris (Araneae: Lycosidae): effects of alternative prey, habitat structure, and density. Basic Appl Ecol 6:471-478 (2005).

83 Vet LE and Dicke M, Ecology of infochemical use by natural enemies in a tritrophic context. Annu Rev Entomo/ 37:141-172 (1992).

84 Inbar $M$ and Gerling D, Plant-mediated interactions between whiteflies, herbivores, and natural enemies. Annu Rev Entomol 53:431-448 (2008)

85 Gnanvossou D, Hanna R and Dicke M, Prey-related odor preference of the predatory mites Typhlodromalus manihoti and Typhlodromalus aripo (Acari: Phytoseiidae). Exp Appl Acarol 27:39-56 (2002).

86 Krrivan V, Effects of optimal antipredator behavior of prey on predator-prey dynamics: the role of refuges. Theor Popul Biol 53:131-142 (1998)

87 Magalhaes S, van Rijn PC, Montserrat M, Pallini A and Sabelis MW, Population dynamics of thrips prey and their mite predators in a refuge. Oecologia 150:557-568 (2007).

88 Chen F, Chen L and Xie X, On a Leslie-Gower predator-prey model incorporating a prey refuge. Nonlinear Anal-Real 10:2905-2908 (2009).

89 Cressman R and Garay JA, Predator - prey refuge system: evolutionary stability in ecological systems. Theor Popul Biol 76:248 (2009).

90 Venzon M, Janssen A, Pallini A and Sabelis MW, Diet of a polyphagous arthropod predator affects refuge seeking of its thrips prey. Anim Behav 60:369-375 (2000).

91 Holt RD and Lawton JH, Apparent competition and enemy-free space in insect host-parasitoid communities. Am Nat 142:623-645 (1993).

92 Butler CD and O'Neil RJ, Defensive response of soybean aphid (Hemiptera: Aphididae) to predation by insidious flower bug (Hemiptera: Anthocoridae). Ann Entomol Soc Am 99:317-320 (2006).

93 Wyckhuys KAG, Stone L, Desneux N, Hoelmer KA, Hopper KR and Heimpel GE, Parasitism of the soybean aphid Aphis glycines by Binodoxys communis: the role of aphid defensive behavior and parasitoid reproductive performance. Bull Entomol Res 98:361-370 (2008).

94 Desneux N, Barta RJ, Hoelmer KA, Hopper KR and Heimpel GE, Multifaceted determinants of host specificity in an aphid parasitoid. Oecologia 160:387-398 (2009).

95 Koss AM, Chang GC and Snyder WE, Predation of green peach aphids by generalist predators in the presence of alternative, Colorado potato beetle egg prey. Biol Control 31:237-244 (2004).

96 Ostman $\mathrm{O}$ and Ives $\mathrm{AR}$, Scale-dependent indirect interactions between two prey species through a shared predator. Oikos 102:505-514 (2003).

97 Rutledge CE, O'Neil RJ, Fox TB and Landis DA, Soybean aphid predators and their use in IPM. Ann Entomol Soc Am 97:240-248 (2004).

98 Desneux N, O'Neil RJ and Yoo HJS, Suppression of population growth of the soybean aphid, Aphis glycines Matsumura, by predators: the identification of a key predator, and the effects of prey dispersion, predator density and temperature. Environ Entomol 35:1342-1349 (2006).

99 Kring TJ and Gilstrap FE, Beneficial role of corn leaf aphid, Rhopalosiphum maidis (Fitch) (Homoptera: Aphididae), in maintaining Hippodamia spp. (Coleoptera: Coccinellidae) in grain sorghum. Crop Prot 5:125-128 (1986).

100 Michels GJ and Matis JH, Corn leaf aphid, Rhopalosiphum maidis (Hemiptera: Aphididae), is a key to greenbug, Schizaphis graminum (Hemiptera: Aphididae), biological control in grain sorghum, Sorghum bicolor. Eur J Entomol 105:513-520 (2008).

101 Yoo HJS and O'Neil RJ, Temporal relationships between the generalist predator, Orius insidiosus, and its two major prey in soybean. Biol Control 48:168-180 (2009).

102 Langer A and Hance T, Enhancing parasitism of wheat aphids through apparent competition: a tool for biological control. Agric Ecosyst Environ 102:205-212 (2004).

103 Stary $P$, Alternative host and parasitoid in 1st method in aphid pest-management in glasshouses. J Appl Entomol 116:187-191 (1993).

104 Parolin P, Bresch C, Desneux N, Brun R, Bout A, Boll R et al., Review of plant types for biological control purposes. Int J Pest Manag 58:91-100 (2012) 
105 Parolin P, Bresch C, Poncet C and Desneux N, Functional characteristics of secondary plants for increased pest management. Int J Pest Manag 58:369-377 (2012).

106 Negloh K, Hanna R and Schausberger P, Comparative demography and diet breadth of Brazilian and African populations of the predatory mite Neoseiulus baraki, a candidate for biological control of coconut mite. Biol Control 48:221-221 (2009).

107 Eitzinger B and Traugott M, Which prey sustains cold-adapted invertebrate generalist predators in arable land? Examining prey choices by molecular gut-content analysis. J Appl Ecol 48:591-599 (2011).

108 Sigsgaard L, Early season natural biological control of insect pests in rice by spiders and some factors in the management of the cropping system that may affect this control, in European Arachnology 2000, Proc 19th Colloquium of Arachnology, ed. by Toft S and Scharff N. Århus University Press, Århus, Denmark, pp. 57-64 (2000).

109 Pereira JL, Picanco MC, Pereira EJG, Silva AA, Jakelaitis A, Pereira RR et al., Influence of crop management practices on bean foliage arthropods. Bull Entomol Res 100:679-688 (2010).

110 Pfannenstiel RS, Unruh TR and Brunner JF, Overwintering hosts for the exotic leafroller parasitoid, Colpoclypeus florus: implications for habitat manipulation to augment biological control of leafrollers in pome fruits. J Insect Sci 10:1 - 13 (2010).

111 Yanik E and Unlu L, Biological traits and prey consumption of Anthocoris minki fed on Agonoscena pistaciae and Brachycaudus (Thuleaphis) amygdalinus. Phytoparasitica 39:333-342 (2011).

112 Doutt RL and Nakata J, The rubus leafhopper and its egg parasitoid: an endemic biotic system useful in grape-pest management. Env iron Entomol 2:381 - 386 (1973).

113 Murphy BC, Rosenheim JA and Granett J, Habitat diversification for improving biological control: abundance of Anagros epos (Hymenoptera: Mymaridae) in grape vineyards. Environ Entomol 25:495-504 (1996).

114 Murphy BC, Rosenheim JA, Dowell RV and Granett J, Habitat diversification tactic for improving biological control: parasitism of the western grape leafhopper. Entomol Exp Applic 87:225-235 (1998).

115 Polis GA and Strong DR, Food web complexity and community dynamics. Am Nat 147:813-846 (1996).

116 Birkhofer K, Wise DH and Scheu S, Subsidy from the detrital food web, but not microhabitat complexity, affects the role of generalist predators in an aboveground herbivore food web. Oikos 117:494-500 (2008)

117 Mathews CR, Bottrell DG and Brown BW, Habitat manipulation of the apple orchard floor to increase ground-dwelling predators and predation of Cydia pomonella (L.) (Lepidoptera: Tortricidae). Biol Control 30:265-273 (2004).

118 Moonen AC and Barberi P, Functional biodiversity: an agroecosystem approach. Agric Ecosyst Environ 127:7-21 (2008).

119 Ratnadass A, Fernandes P, Avelino J and Habib R, Plant species diversity for sustainable management of crop pests and diseases in agroecosystems: a review. Agron Sustain Dev 32:273-303 (2012).

120 Holt RD, Grover J and Tilman D, Simple rules for interspecific dominance in systems with exploitative and apparent competition. $A m$ Nat 144:741-771 (1994).

121 Rosenzweig ML, The paradox of enrichment: destabilization of exploitation ecosystems in ecological time. Science 171:385-387 (1971).

122 Abrams PA and Walters CJ, Invulnerable prey and the paradox of enrichment. Ecology 77:1125-1133 (1996).

123 DeCesare NJ, Hebblewhite M, Robinson HS and Musiani M, Endangered, apparently: the role of apparent competition in endangered species conservation. Anim Conserv 13:353-362 (2010).

124 Cronin JT, Shared parasitoids in a metacommunity: indirect interactions inhibit herbivore membership in local communities. Ecology 88:2977-2990 (2007).

125 Snyder WE, Clevenger GM and Eigenbrode SD, Intraguild predation and successful invasion by introduced ladybird beetles. Oecologia 140:559-565 (2004)

126 Chacon JM and Heimpel GE, Density-dependent intraguild predation of an aphid parasitoid. Oecologia 164:213-220 (2010).

127 Dinter A, Intraguild predation between erigonid spiders, lacewing larvae and carabids. J Appl Entomol 122:163-167 (1998).

128 Onzo A, Hanna R, Negloh K, Toko M and Sabelis MW, Biological control of cassava green mite with exotic and indigenous phytoseiid predators - effects of intraguild predation and supplementary food. Biol Control 33:143-152 (2005).
129 Rickers S, Langel R and Scheu S, Stable isotope analyses document intraguild predation in wolf spiders (Araneae: Lycosidae) and underline beneficial effects of alternative prey and microhabitat structure on intraguild prey survival. Oikos 114:471-478 (2006).

130 Langellotto GA and Denno RF, Refuge from cannibalism in complex-structured habitats: implications for the accumulation of invertebrate predators. Ecol Entomol 31:575-581 (2006).

131 Frank SD, Shrewsbury PM and Denno RF, Effects of alternative food on cannibalism and herbivore suppression by carabid larvae. Ecol Entomol 35:61-68 (2010).

132 Batzer DP and Wissinger SA, Ecology of insect communities in nontidal wetlands. Annu Rev Entomol 41:75-100 (1996).

133 Finke $\mathrm{DL}$ and Denno RF, Intra-guild predation relaxes natural enemy impacts on herbivore populations. Ecol Entomol 28:67-73 (2003).

134 Claessen D, de Roos AM and Persson L, Population dynamic theory of size-dependent cannibalism. Proc R Soc Lond B Biol 271:333-340 (2004).

135 Lima SL, Vigilance while feeding and its relation to the risk of predation. J Theor Biol 124:303-316 (1987).

136 Lima SL and Dill LM, Behavioral decisions made under the risk of predation - a review and prospectus. Can J Zool 68:619-640 (1990).

137 Chailleux A, Bearez P, Pizzol J, Amiens-Desneux E, Ramirez-Romero $\mathrm{R}$ and Desneux N, Potential for combined use of parasitoids and generalist predators for biological control of the key invasive tomato pest Tuta absoluta. J Pest Sci 86:533-541 (2013).

138 Chailleux A, Biondi A, Han P, Tabone E and Desneux N, Suitability of the pest-plant system Tuta absoluta (Lepidoptera: Gelechiidae)-tomato for Trichogramma (Hymenoptera: Trichogrammatidae) parasitoids and insights for biological control. $J$ Econ Entomol 106:2310-2321 (2013).

139 Janssen A, Montserrat M, HilleRisLambers R, de Roos AM, Pallini A and Sabelis MW, Intraguild predation usually does not disrupt biological control, in Trophic and Guild Interactions in Biological Control, ed. by Brodeur J and Boivin G. Springer, Dordrecht, The Netherlands, pp. 21-44 (2006).

140 Van Nouhuys $S$ and Hanski I, Apparent competition between parasitoids mediated by an hyperparasitoid. Ecol Lett 3:82-84 (2000).

141 Abrams PA, Indirect interactions between species that share a predator: varieties of indirect effects, in Predation: Direct and Indirect Impacts on Aquatic Communities, ed. by Kerfott W and Sih A. University Press of New England, Lebanon, NH, pp. 38-54 (1987).

142 Abrams PA, The adaptive dynamics of consumer choice. Am Nat 153:83-97 (1999).

143 Křivan V and Sikder A, Optimal foraging and predator-prey dynamics, II. Theor Popul Biol 55:111-126 (1999).

144 Bonsall MB and Holt RD, The effects of enrichment on the dynamics of apparent competitive interactions in stage-structured systems. Am Nat 162:780-795 (2003).

145 Krrivan V and Eisner J, The effect of the Holling type II functional response on apparent competition. Theor Popul Biol 70:421-430 (2006).

146 Bate AM and Hilker FM, Rabbits protecting birds: hypopredation and limitations of hyperpredation. J Theor Biol 297:103-115 (2012).

147 Abrams PA and Kawecki T, Adaptive host preference and the dynamics of host-parasitoid interactions. Theor Popul Biol 56:307-324 (1999).

148 Abrams PA and Matsuda $\mathrm{H}$, Population dynamical consequences of reduced predator switching at low total prey densities. Popul Biol 45:175-185 (2003)

149 Abrams PA and Matsuda $\mathrm{H}$, Consequences of behavioral dynamics for the population dynamics of predator-prey systems with switching. Popul Ecol 46:13-25 (2004).

150 Berec L, Eisner J and Křivan V, Adaptive foraging does not always lead to more complex food webs. J Theor Biol 266:211-218 (2010).

151 Křivan V, Competitive co-existence caused by adaptive predators. Evol Ecol Res 5:1163-1182 (2003).

152 Křivan V and Schmitz O, Adaptative foraging and flexible food web topology. Evol Ecol Res 5:623-652 (2003).

153 Křivan V and Eisner J, Optimal foraging and predator - prey dynamics III. Theor Popul Biol 63:269-279 (2003). 
154 van Baalen M, Křivan V, van Rijn PC and Sabelis MW, Alternative food, switching predators, and the persistence of predator-prey systems. Am Nat 157:512-524 (2001).

155 Holt RD and M Barfield, Impacts of temporal variation on apparent competition and coexistence in open ecosystems. Oikos 101:49-58 (2003).

156 Holt RD, Community modules, in Multitrophic Interactions in Terrestrial Systems, ed. by Gange AC and Brown VK. Blackwell Science, Oxford, UK, pp. 333-349 (1997).

157 Holt RD and Hochberg ME, Indirect interactions, community modules and biological control: a theoretical perspective, in Evaluating Indirect Ecological Effects of Biological Control, ed. by Wajnberg E, Scott JK and Quimby PC. CABI International, Wallingford, Oxon, UK, pp. 13-37 (2001).
158 Tilman D, Mechanisms of plant competition of nutrients: the elements of a predictive theory of competition, in Perspectives on Plant Competition, ed. by Grace J and Tilman D. Academic Press, New York, NY, pp. 117-142 (1990).

159 Bunemann EK, Schwenke GD and Van Zwieten L, Impact of agricultural inputs on soil organisms - a review. Aust J Soil Res 44:379-406 (2006).

160 Desneux N, Decourtye A and Delpuech JM, The sublethal effects of pesticides on beneficial arthropods. Annu Rev Entomol 52:81 - 106 (2007).

161 Landis DA, Wratten SD and Gurr GM, Habitat management to conserve natural enemies of arthropod pests. Annu Rev Entomol 45:175-201 (2000). 